\title{
Correspondence
}

Epidemiol. Infect. (2017).

doi:10.1017/S0950268817000061

First published online 16 February 2017

\section{Decreasing the hepatitis B burden in Tunisia need more attention to adults for vaccination}

\section{Dear Editor,}

I read with interest the published article by Chaouch et al. [1] in your journal recently. Their study in student with age of 12-21 years in public colleges and after 17 years of hepatitis B virus (HBV) vaccination showed no hepatitis B surface antigen ( $\mathrm{HBsAg}$ )positive individual and the overall seroprotection rate around $68.9 \%$ in vaccinated subjects. It was interesting that the HBsAg was negative in un-vaccinated group too and the rate of anti-HBcAb (hepatitis B core antibody) was 1.4 in un-vaccinated group. It means that the main risk factor for HBV is horizontal in Tunisia. They reported that nine cases had antihepatitis B surface antibody ( $\mathrm{HBs} A$ b) positive and two of them were $<10 \mathrm{IU} / \mathrm{ml}$. I think they should put these two cases in negative group according the standard of anti-HBsAb testing. In a systematic review after 22 years of Iranian Expanded Program on Immunization (EPI), overall $80 \%$ were responder to $\mathrm{HBV}$ vaccine and with increase in age, the number of responders to vaccine decreased significantly [2] and there was no strong difference between responders $v s$. Non-responders to vaccine for gender, types of vaccine, ethnicity and living area [2]. Another study in among medical students after 18-22 years of vaccination showed that about $57 \%$ of the study group had anti-HBsAb level of 100-1000 mIU/ml. No significant association was found between anti-HBs level and age, sex, and locality [3]. These studies were done in countries where the main risk factor for HBV infection was vertical transmission from pregnant mothers to their infants. I think, it was better in Chaouch et al. study [1] for grouping the level of
anti-HBsAb to $<10$, between 10 and 100 and more than 100 in analysis.

The other studies from Tunisia in infants and children under 5 years and adolescents suggested that vertical and perinatal transmission of HBV does not appear to be significant in Tunisia [4]. However, I would like to suggest for more studies in adolescents for finding the main risk factors in general population higher age than 25 years and vaccinate the adult as we did in our country before and we confirmed that strategy was effective in decreasing the HBV burden in our community [5].

\section{References}

1. Chaouch H, et al. Impact and long-term protection of hepatitis B vaccination: 17 years after universal hepatitis $\mathrm{B}$ vaccination in Tunisia. Epidemiology and Infection 2016; 18: 1-11.

2. Rezaee R, et al. Prevalence of national responsiveness to HBV vaccine after 22 years of Iranian expanded program on immunization (EPI): a systematic review and meta-analysis study. Hepatitis Monthly 2015; 15: e23618.

3. Dumaidi K, Al-Jawabreh A. Persistence of anti-HBs among Palestinian medical students after 18-22 years of vaccination: a cross-sectional study. Hepatitis Monthly 2015; 15: e29325.

4. Triki H, et al. Seroepidemiology of hepatitis B, C and delta viruses in Tunisia. Transactions of the Royal Society of Tropical Medicine and Hygiene 1997; 91: 11-4.

5. Mirrezaie SM, et al. Impact of HBV vaccination on prevalence of hepatitis B virus infection among volunteer blood donors in Tehran-Iran. Shiraz E-Medical Journal 2014; 15: e18066.

S. M. ALAVIAN*

Baqiyatallah Research Center for Gastroenterology and Liver Disease, Tehran, Islamic Republic of Iran

*Author for correspondence: S. M. Alavian, M. D., Baqiyatallah Research Center for Gastroenterology and Hepatology and Liver Disease, P.O. Box 14155/3651, Tehran, Islamic Republic of Iran.

(Email: alavian@thc.ir) 